\title{
Assessing joint effusion and bone changes of the head of the mandible in MR images of symptomatic patients
}

\section{Jefferson Xavier de Oliveira Jucely Aparecida da Rosa Marcelo Eduardo Pereira Dutra Karina Cecilia Panelli Santos Cibelle Gil}

Discipline of Dental Radiology, Department of Stomatology, School of Dentistry, Univ de São Paulo - USP, São Paulo, SP, Brazil.
Declaration of Interests: The authors certify that they have no commercial or associative interest that represents a conflict of interest in connection with the manuscript.

Corresponding Author: Jucely Aparecida da Rosa E-mail: jucelyaparecida@usp.br

Submitted: Jul 17, 2012

Accepted for publication: Sep 26, 2012

Last revision: Sep 29, 2012

\begin{abstract}
The aim of the present study was to investigate the relationship between degenerative bone changes of the head of the mandible and the presence of joint effusion (JE). This study was based on sagittal magnetic resonance imaging (MRI) reports of 148 temporomandibular joints (TMJs) of 74 patients complaining of pain and/or dysfunction in the TMJ area. The mandible heads were surveyed for osteoarthritis characteristics, which were classified as osteophytosis, sclerosis or erosion. The presence of JE was checked whenever high signal intensity was observed in the articular space. The results evidenced the presence of bone changes in $30 \%$ of the sample. Osteophytes and erosions were the changes most commonly observed. JE was reported in $10 \%$ of TMJs. The results from the statistical tests revealed that bone changes in the head of the mandible are associated with the presence of JE.
\end{abstract}

Descriptors: Magnetic Resonance Imaging; Temporomandibular Joint; Osteoarthritis.

\section{Introduction}

Magnetic resonance imaging (MRI) provides an excellent representation of soft tissues in anatomical and semi-functional relationships. The multi-section images it generates allow a tridimensional analysis of the temporomandibular joint (TMJ), providing the most complete assessment of the relationship between TMJ components. ${ }^{1}$

Examination by MRI may be used to analyze the articular disc position in the coronal and parasagittal planes, the translation movement of the head of the mandible, and the disc movement during mouth opening and closing. MRI may also be used to detect the presence of effusion, bone erosions and degenerative diseases. ${ }^{2,3}$

Joint effusion (JE) is generally defined as a pathological collection of fluid in articular spaces. It appears in MR images as high signal intensity in the TMJ space, observed on T2-weighted images. It often appears accompanied by disc displacement (DD) and by pathological changes, such as inflammatory processes or synovitis, and is considered a very useful indicator in assessing the progression and severity of temporomandibular dysfunction (TMD). ${ }^{4}$

Degenerative bone changes of the TMJ are significantly more frequent in the head of the mandible than in the articular eminence, and are characterized by the development of osteophytes, erosions, avascular necro- 
ses, subchondrial cysts and intra-articular foreign bodies. ${ }^{4,5}$ These changes are considered radiological signs of osteoarthritis (OA), and have been observed in symptomatic TMJs. ${ }^{5,6}$

If a strong association between the presence of JE and OA were to be established, this could be the basis for valuable additional diagnostic information. The aim of this study was thus to investigate the relationships between OA in the head of the mandible and the presence of JE, by analyzing MR images of the TMJs of symptomatic patients.

\section{Methodology}

MR images of 148 TMJs from 74 adult patients submitted to this examination after indication by their dentists or physicians were used. The images were retrieved from the archives of a private institution. The inclusion criterion was the presence of at least one sign or symptom of TMD reported during clinical examination. Patients who reported any systemic involvement or who were using medication that could entail bone changes were disregarded.

The exams were performed with a Signa apparatus (GE Medical Systems, Madison, USA) with 1.5 Tesla field strength, using T2 and PD weighted sequences, with the aid of a double surface coil $20 \mathrm{~cm}$ in diameter (GE Medical Systems, Madison, USA). The images were obtained in the sagittal plane with 3-mm-thick cuts, saved in DICOM format and evaluated by two experienced radiologists (a physician and a dentist). Each of them evaluated the images only once and the resulting reports were obtained by consensus.

The mandible heads were surveyed for OA characteristics, which were classified as osteophytosis, sclerosis or erosion.

The presence of JE was checked in the T2weighted images whenever high signal intensity was observed in the articular space (Figure 1).

The study was approved by the Research Ethics Committee, University of São Paulo, under protocol 119/2009.

The conditions assessed were recorded as present or absent, and then submitted to descriptive statistics. The data regarding gender, OA of the mandible head and presence of JE were analyzed through ab- solute and relative frequency calculation, and then plotted in charts. Following the descriptive analysis, Fisher's exact test was performed to ascertain whether the OA characteristics of the mandible heads were associated with the presence of JE, at a significance level of $5 \%(\mathrm{P}<0.05)$. The statistical analyses were conducted with Statistical Package for Social Sciences software (SPSS for Windows, version 11.0, Chicago, USA).

\section{Results}

From the 74 patients evaluated (148 TMJs), 51 (68.9\%) were female, and $23(31.1 \%)$ were male. The mean age of female patients was $40.4 \pm 14.5$ years (range: 13-69 years). The mean age of male patients was $35.9 \pm 11.2$ years (range: $17-58$ years).

The TMJs were assessed bilaterally for the occurrence of OA and JE. OA characteristics were observed in $30 \%$ of the samples (Figure 2), the most frequent of which were osteophytosis $(\mathrm{n}=13,9 \%)$ and sclerosis $(\mathrm{n}=8,5 \%)$; erosion was the least frequent change observed $(\mathrm{n}=1,1 \%)$. The OA characteristics observed were associated, as follows:

- erosion and osteophytosis $(\mathrm{n}=8,6 \%)$;

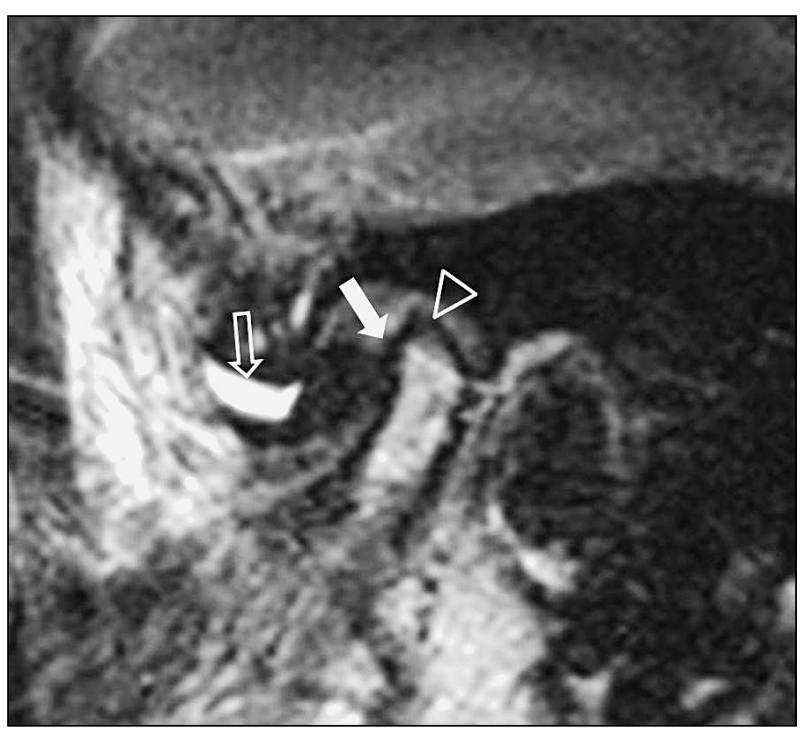

Figure 1 - T2-weighted image presenting signal loss of medullary bone of the head of the mandible and temporal articular eminence (osteoarthritis - white filled arrow), as well as high signal intensity in the posterior articular space (joint effusion - white empty arrow). Erosion of the superior pole of the head of the mandible may also be observed (arrow head). 


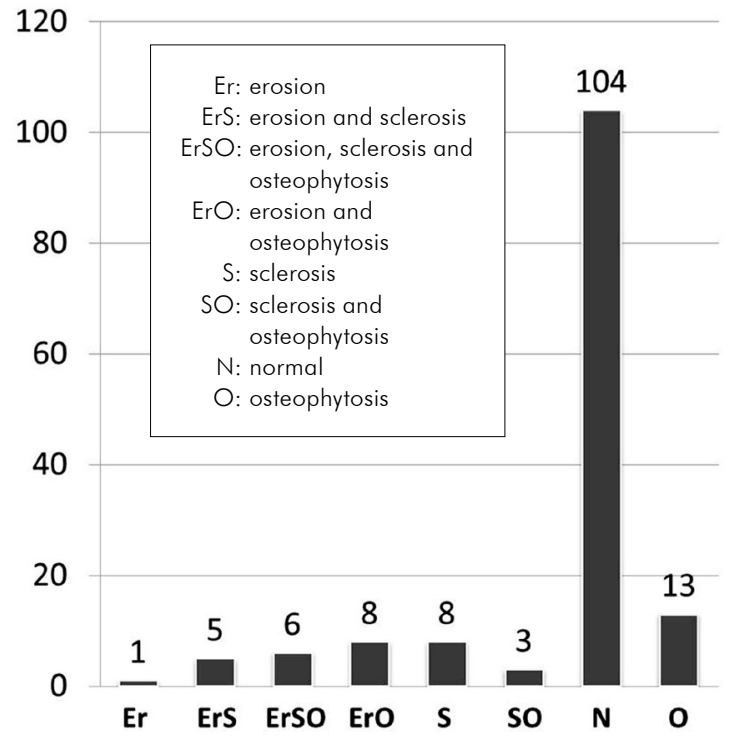

Figure 2 - Distribution of TMJs according to bone changes of the head of the mandible.

- erosion, sclerosis and osteophytosis $(\mathrm{n}=6,4 \%)$;

- erosion and sclerosis ( $\mathrm{n}=5,3 \%)$; and

- sclerosis and osteophytosis $(\mathrm{n}=3,2 \%)$.

JE was observed in $10 \%$ of the samples, as shown in Figure 3.

Table 1 illustrates the descriptive analysis of the association between $\mathrm{OA}$ characteristics and the presence of JE.

The results of the statistical tests revealed that the OA characteristics of the head of the mandible were associated with the presence of JE $(\mathrm{p}=0.006)$. Subjects with JE on at least one side presented the same OA profile $(\mathrm{p}=0.835)$. Subjects with no JE on either side presented a higher rate of TMJs with no OA, on both sides, when compared to patients with $\mathrm{JE}$ on at least one side $(\mathrm{p}=0.048)$.

\section{Discussion}

MRI is considered a choice method to assess the soft components of joints, as well as changes in the quantity of articular fluid. ${ }^{5,7}$

The present study assessed the relationship between mandibular condyle $\mathrm{OA}$ and the presence of JE. MRI is a reliable method to detect JE. ${ }^{8}$ Bone changes may be assessed by viewing the TMJ in the position used in this examination with an accuracy

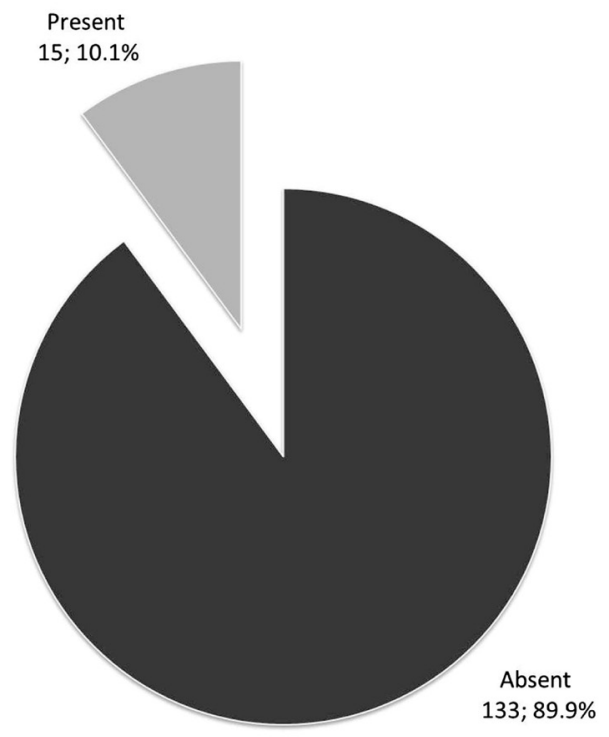

Figure 3 - Distribution of TMJs according to JE presence.

of $93 \% .^{3}$

The inclusion criterion was the presence of pain in the TMJ or in the neighboring temporal, frontal or auricular regions. Studies found in the related literature show a strong correlation between TMJ pain, disc displacement and JE. ${ }^{6,9}$ Pain persisting after TMJ arthrocentesis is generally related to a great amount of JE and erosive condylar OA. ${ }^{9}$ There are, however, several studies showing a weak correlation between JE and TMJ pain. ${ }^{10,11}$ Furthermore, JE has also been detected in asymptomatic TMJs, with no observable pathology. ${ }^{12}$

We also observed a predominance of female over male subjects, an observation consistent with a tendency reported in the related literature. . $, 6,13,14$

Osteoarthritis, on the other hand, was observed in $30 \%$ of the samples, which is in agreement with other studies stating that bone abnormalities are not always related to symptom reports by patients. ${ }^{5,9} \mathrm{We}$ also observed that the condylar OA characteristics were associated, predominated by the erosion/osteophyte combination. This finding is corroborated by a study reporting a higher frequency of osteophytes and erosions combined. ${ }^{5}$

JE was found in $10.1 \%$ of subjects, which agrees with the findings of another study reporting this same percentage in symptomatic patients. ${ }^{12}$ The 
Table 1 - Distribution of subjects according to bone changes of the head of the mandible and the presence of intraarticular effusion.

AA: absent on both sides; AP: absent on the right side and present on the left side; PA: present on the right side and absent on the left side; PP: present on both sides; ErS ErS: erosion and sclerosis on both sides; $\mathrm{ErS} \mathrm{N}$ : erosion and sclerosis on one side and normal on the other side; ErSO S: erosion, sclerosis and osteophytosis on one side and sclerosis on the other side; $\mathrm{ErSO} \mathrm{N}$ : erosion, sclerosis and osteophytosis on one side and normal on the other side; ErSO O: erosion, sclerosis and osteophytosis on one side and osteophytosis on the other side; $\mathrm{ErO} \mathrm{ErO}$ : erosion and osteophytosis on both sides; ErO S: erosion and osteophytosis on one side and sclerosis on the other side; $\mathrm{ErO} \mathrm{N}$ : erosion and osteophytosis on one side and normal on the other side; $\mathrm{ErO} \mathrm{O}$ : erosion and osteophytosis on one side and osteophytosis on the other side; S S: sclerosis on both sides; SO S: sclerosis and osteophytosis on one side and sclerosis on the other side; SO N: sclerosis and osteophytosis on one side and normal on the other side; $\mathrm{N}$ Er: normal on one side and erosion on the other side; N S: normal on one side and sclerosis on the other side; $\mathrm{N} \mathrm{N}$ : normal on both sides; $\mathrm{N} \mathrm{O}$ : normal on one side and osteophytosis on the other side; $\mathrm{O}$ : osteophytosis on both sides.

\begin{tabular}{|c|c|c|c|c|c|c|c|c|c|c|}
\hline \multirow{3}{*}{$\begin{array}{c}\text { Bone change } \\
\text { status }\end{array}$} & \multicolumn{8}{|c|}{ Intra-articular effusion status } & \multirow{2}{*}{\multicolumn{2}{|c|}{ Total }} \\
\hline & \multicolumn{2}{|c|}{$A A$} & \multirow{2}{*}{\multicolumn{2}{|c|}{$\begin{array}{c}\text { A P } \\
-\end{array}$}} & \multirow{2}{*}{\multicolumn{2}{|c|}{$\begin{array}{c}\text { PA } \\
-\end{array}$}} & \multirow{2}{*}{\multicolumn{2}{|c|}{$\begin{array}{c}\text { P P } \\
-\end{array}$}} & & \\
\hline & 1 & (1.6\%) & & & & & & & 1 & $(1.4 \%)$ \\
\hline ErS N & 3 & (4.8\%) & & - & & - & & - & 3 & $(4.1 \%)$ \\
\hline $\mathrm{ErSO} \mathrm{S}$ & \multicolumn{2}{|r|}{-} & & $(20.0 \%)$ & & - & & - & 1 & $(1.4 \%)$ \\
\hline $\mathrm{ErSO} \mathrm{N}$ & 2 & $(3.2 \%)$ & & - & 1 & $(50.0 \%)$ & 1 & $(25.0 \%)$ & 4 & $(5.4 \%)$ \\
\hline $\mathrm{ErSO} \bigcirc$ & \multicolumn{2}{|r|}{-} & \multicolumn{2}{|r|}{-} & \multicolumn{2}{|c|}{$1 \quad(50.0 \%)$} & \multicolumn{2}{|r|}{-} & 1 & (1.4\%) \\
\hline $\mathrm{ErO} \mathrm{ErO}$ & 1 & $(1.6 \%)$ & & - & & - & & - & 1 & $(1.4 \%)$ \\
\hline $\mathrm{ErOS}$ & \multicolumn{2}{|r|}{-} & \multicolumn{2}{|r|}{-} & \multicolumn{2}{|r|}{-} & \multicolumn{2}{|c|}{$1 \quad(25.0 \%)$} & \multicolumn{2}{|c|}{$1 \quad(1.4 \%$} \\
\hline $\mathrm{ErON}$ & 4 & (6.3\%) & & - & & - & & - & 4 & $(5.4 \%)$ \\
\hline $\mathrm{ErO} O$ & 1 & $(1.6 \%)$ & & - & & - & & - & 1 & $(1.4 \%)$ \\
\hline S S & 2 & $(3.2 \%)$ & & - & & - & & - & 2 & $(2.7 \%)$ \\
\hline $\mathrm{sOS}$ & \multicolumn{2}{|r|}{-} & \multicolumn{2}{|c|}{$1 \quad(20.0 \%)$} & \multicolumn{2}{|r|}{-} & \multicolumn{2}{|r|}{-} & 1 & (1.4\%) \\
\hline $\mathrm{SON}$ & 2 & $(3.2 \%)$ & & - & & - & & - & 2 & $(2.7 \%)$ \\
\hline $\mathrm{NEr}$ & \multicolumn{2}{|r|}{-} & \multicolumn{2}{|r|}{-} & \multicolumn{2}{|r|}{-} & \multicolumn{2}{|c|}{$1 \quad(25.0 \%)$} & 1 & (1.4\%) \\
\hline N S & & (1.6\%) & & - & & - & & - & 1 & (1.4\%) \\
\hline $\mathrm{NN}$ & 39 & (61.9\%) & 2 & $(40.0 \%)$ & & - & & $(25.0 \%)$ & 42 & $(56.8 \%)$ \\
\hline $\mathrm{NO}$ & 4 & $(6.3 \%)$ & & $(20.0 \%)$ & & - & & - & 5 & $(6.8 \%)$ \\
\hline$\bigcirc \bigcirc$ & 3 & $(4.8 \%)$ & & - & & - & & - & 3 & $(4.1 \%)$ \\
\hline Total & 63 & $100.0 \%$ & & (100.0\%) & & (100.0\%) & & (100.0\%) & 74 & $(100.0 \%)$ \\
\hline
\end{tabular}

minute size of the intra-articular space and the similarity between the synovial liquid and the JE signals on MR images make it difficult to distinguish these signals. Furthermore, there is no consensus on the amount of fluid that would be involved in safely characterizing a JE. ${ }^{2}$ The criterion used in our study to make the distinction between effusion and synovial liquid was high signal intensity in the intraarticular space in T2-weighted images. No quantitative analysis of fluids was performed; only the presence or absence of JE was detected.

The statistical results showed that condylar OA characteristics were associated with the presence of TMJ effusion $(\mathrm{p}=0.006)$. However, JE was also

\section{References}

1. Hirata FH, Guimarães AS, Oliveira JX, Moreira CR, Ferreira ET, Cavalcanti MG. Evaluation of TMJ articular eminence morphology and disc patterns in patients with disc displacement in MRI. Braz Oral Res. 2007 Jul-Sep;21(3):265-71. observed in normal TMJs. Hence, additional data may be necessary to confirm this relationship and to ascertain whether OA characteristics are initial or contributing factors in the onset of JE.

\section{Conclusion}

According to the results obtained in this study, the incidence of JE was correlated to OA characteristics of the head of the mandible. Erosions and osteophytes were the most frequently observed mandibular condyle OA characteristics. However, most symptomatic patients evaluated showed neither bone alterations nor signal intensity consistent with joint effusion.

2. Orlando B, Chiappe G, Landi N, Bosco M. Risk of temporomandibular joint effusion related to magnetic resonance imaging signs of disc displacement. Med Oral Patol Oral Cir Bucal. 2009 Apr 1;14(4):E188-93. 
3. Tasaki MM, Westesson PL. Temporomandibular joint: diagnostic accuracy with sagittal and coronal MR imaging. Radiology. 1993 Mar;186(3):723-9.

4. Zarb GA, Carlsson GE. Temporomandibular disorders: osteoarthritis. J Orofac Pain. 1999;13(4):295-306.

5. Campos MI, Campos PS, Cangussu MC, Guimarães RC, Line SR. Analysis of magnetic resonance imaging characteristics and pain in temporomandibular joints with and without degenerative changes of the condyle. Int J Oral Maxillofac Surg. 2008 Jun;37(6):529-34.

6. Emshoff R, Brandimaier I, Bertram S, Rudisch A. Magnetic resonance imaging findings of osteoarthrosis and effusion in patients with unilateral temporomandibular joint pain. Int J Oral Maxillofac Surg. 2002 Dec;31(6):598-602.

7. Payne M, Nakielny RA. Temporomandibular joint imaging. Clin Radiol. 1996 Jan;51(1):1-10.

8. Ahmad M, Hollender L, Anderson Q, Kartha K, Ohrbach $\mathrm{R}$, Truelove EL, et al. Research diagnostic criteria for temporomandibular disorders (RDC/TMD): development of image analysis criteria and examiner reliability for image analysis. Oral Surg Oral Med Oral Pathol Oral Radiol Endod. 2009 Jun;107(6):844-60.

9. Honda K, Yasukawa Y, Fujiwara M, Abe T, Urade M. Causes of persistent joint pain after arthrocentesis of temporomandibular joint. J Oral Maxillofac Surg. 2011 Sep;69(9):2311-5.
10. Adame CG, Monje F, Offnoz M, Martin-Granizo R. Effusion in magnetic resonance imaging of the temporomandibular joint: a study of 123 joints. J Oral Maxillofac Surg. 1998 Mar;56(3):314-8.

11. Murakami K, Nishida M, Bessho K, Iizuka T, Tsuda Y, Konishi J. MRI evidence of high signal intensity and temporomandibular arthralgia and relating pain. Does the high signal correlate to the pain?. Br J Oral Maxillofac Surg. 1996 Jun;34(3):220-4.

12. Larheim TA, Katzberg RW, Westesson PL, Tallents RH, Moss ME. MR evidence of temporomandibular joint fluid and condyle marrow alterations: occurrence in asymptomatic volunteers and symptomatic patients. Int J Oral Maxillofac Surg. 2001 Apr;30(2):113-7.

13. Emshoff R, Brandlmaier I, Bertram S, Rudisch A. Risk factors for temporomanibular joint pain in patients with disc displacement without reduction - a magnetic resonance imaging study. J Oral Rehabil. 2003 May;30(5):537-43.

14. Ogutcen-Toller M, Taskava-Yilmaz N, Yilmaz F. The evaluation of temporomandibular joint disc position in TMJ disorders using MRI. Int J Oral Maxillofac Surg. 2002 Dec;31(6):603-7. 